\title{
Design and Implementation of Tower of Hanoi Gaming Courseware Based on the Internet
}

\author{
Li Qianwen, Zhang Xuegang, Tang Runhua \\ Guangdong food and drug vocational college \\ GuangZhou, China \\ zhangxg@gdyzy.edu.cn
}

\begin{abstract}
Online game-based courseware is courseware that optimized combines instructiveness and entertainment. Design and development of practical, lively and effective online game-based courseware is a practical significance to explore in the field of modern education technology. Design Research of Tower of Hanoi Gaming courseware is to design a tower of Hanoi gaming courseware to solve the teaching difficulty of recursive problem in the $C$ language course. The new kind of courseware blend instructional design in the game, which leads to the picturesque understanding of knowledge in the process of the game.
\end{abstract}

Keywords- Tower of Hanoi problem; Gaming courseware; Design of courseware; Online game-based courseware; Human-Computer Interaction

\section{PREFACE}

Most of the network education resources at present domestic education web sites usually use simple textual resources, or video resources. These resources are all in a simplex form lack the necessary human-computer interaction and are not able to provide students with a vivid, effective and practical learning situation. These problems have now become bottlenecks in the development of contemporary network education. The emergence of online game-based courseware in recent years provides us with a better solution to the problem ${ }^{[1]}$. Compared with the traditional courseware, online gamebased courseware has its special significance to teaching. Online game-based courseware introduced elements of games into courseware, which has realized the effective combination of instructiveness and entertainment ${ }^{[2]}$. Moreover, online game-based courseware utilize the openness network to provide students with a realistic simulation learning scenarios that can make teaching operable and interesting, in the course of the game unwittingly acquire new knowledge $\mathrm{e}^{[3]}$.

There are also Tower of Hanoi games on the Internet, but their weakness is that they have only entertainment without instructiveness. After they finish off the game, the players do not know the mathematical principles they used to solve the problem. Tower of Hanoi problem is one of the challenges and focuses $\mathrm{C}$ language course, the recursive principle it implied plays a key role in computational mathematics. Solution to this problem is important for the further study and development of students' intelligence. However, the existing online Tower of Hanoi games cannot meet this requirement. Thus, in order to utilize Tower of Hanoi game as a tool to enable learners having a profound understanding of the principles of recursive, we designed and implemented the online game-based courseware.

\section{CHARACTERISTICS OF ONLINE GAME-BASED COURSEWARE}

Online game-based courseware is a web-based and entertaining educational game software ${ }^{[4]}$. In the form of the game, it raises students' interest in learning, enables students to acquire academic knowledge through the game and form capabilities, and has a high value in teaching. Compared with traditional courseware, Online game-based courseware has incomparable advantages as follows: (1) Narrative and interesting way of presenting course content: Online game-based courseware make abstract teaching content specific, so that students could learn knowledge with interest. (2) Virtualization and Visualization of the Learning environment: Online game-based courseware can easily simulate realistic learning environment so that students immersed in a virtual learning environment, which will improve their efficiency of learning. (3) Invisible mode of knowledge dissemination: Online gamebased courseware does not directly teach contents, but let the learners participate in the game to explore their own knowledge. The knowledge dissemination process is imperceptible. (4) Operability of learning process: Online game-based courseware provides timely interaction, student-controlled learning situation, so that students can actively control the learning process and improve the efficiency of learning..

\section{DESIGN OF ONLINE GAME-BASED COURSEWARE}

Design is the basic link of producing online gamebased courseware ${ }^{[5]}$. The overall idea is to combine online game and courseware to create a virtual immersive learning situation, in which students can autonomously threw themselves into learning and cultivate their explorative capability. Therefore, in the design of courseware, pay attention to the relevant elements of the game introduced to the courseware, and eventually turn the abstract knowledge into a concrete operable game.

\section{TASK DESIGN}

\section{A. Task Design}

Core of task design is to enable students to understand the nature of the recursion and the thinking of problem solving by letting students to solve the tower of Hanoi problem. In the $C$ language courses, complicated steps and tasks are the main reason why tower of Hanoi problem puzzling teachers and students. Students usually learn to solve the problem only by the conception in mind, which 
often leads to confusion. On the other hand, while teachers are teaching the problem, solving process is too difficult to be demonstrated to the students due to the excessively tedious steps. Online game-based courseware can be a good solution to both problems. Online game-based courseware can achieve the desired effect of teaching by letting students to take the initiative to explore the operation and letting them see the process of their operation, which, cannot be achieved via existing online tower of Hanoi games.

In the beginning of task design, let's analysis the problem of tower of Hanoi.

The Tower of Hanoi consists of three rods, and a number of disks of different size, which can slide onto any rod. The puzzle starts with the disks in a neat stack in ascending order of size on one rod, the smallest at the top, thus making a conical shape. The objective of the puzzle is to move the entire stack to another rod, obeying the following simple rules:

(1)Only one disk can be moved at a time.

(2)Each move consists of taking the upper disk from one of the stacks and placing it on top of another stack i.e. a disk can only be moved if it is the uppermost disk on a stack.

(3)No disk may be placed on top of a smaller disk. ${ }^{[6]}$

The final step of the requirements of the online gamebased courseware is to write a program to display moving. Thus, the tasks to solve the Tower of Hanoi problem are as follows:

Task 1: Find the relationship between the number of disks and the position of the first movement. Succeeding in this task would be conductive to continue the exploratory procedure.

Task 2: Find the relationship between the number of disks and the position of the first movement. Succeeding in this task would enable students to understand how many steps would be needed to move a certain number of disks, so that students could get a quantitative understanding of the task.

Task 3: Give tips in the key step of the tasks, so that the students would be able to grasp the general idea to solve Tower of Hanoi problem.

Task 4: Summarize the general idea of solving Tower of Hanoi problem. Through leading questions, let the students gradually summed up the general idea to solve the problem on their own, so that students could fully understand the essence of the principle of recursion.

\section{B. Structural Design}

Goal of structural design is to determine the organization and expression of online tower-of-Hanoigame-based courseware. It defines the relationship between the various parts of the courseware content, and how they relate. Also, it defines the relationship between the various parts of the learning content, and how they relate. Structure of the courseware reflects the basic style of the courseware and is related to the readability and the possibility of post-construction of the courseware.

According to the reasons above, the structure of online tower-of-Hanoi-game-based courseware can be designed as shown in FIG. 1.

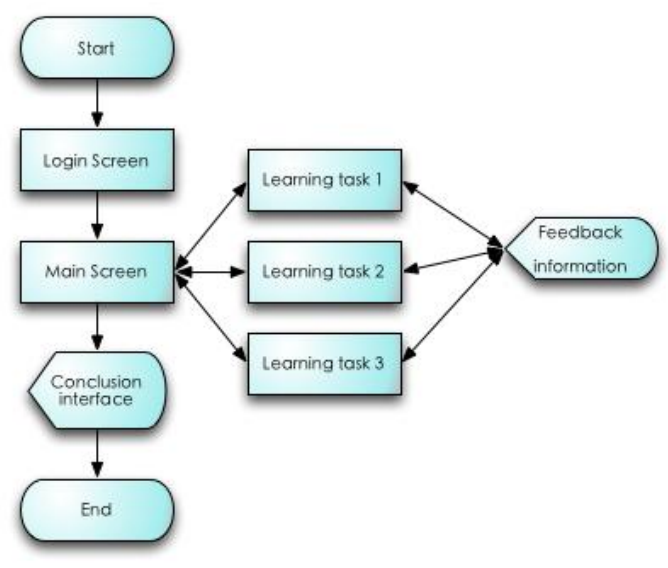

Figure 1. the structure chart of Hanoi Gaming Courseware

\section{Interface Design}

Interface design is not only a simple combination of windows, graphics or menus, but also an interactive interface with high availability and learnability, which is created to focus the attention of students and to meet student needs. Therefore, interface design of the online tower-of-Hanoi-game-based courseware is very important.

We, during interface design, should pay attention to the following two aspects:

On one hand, the interface design should be simple and clear. Simple user interface gives students a light mood, and allows students to learn in a calming situation. On the other hand, the interface should look harmony and let the students feel beauty from the interface, so that the students can easily put themselves into the game-based courseware operation.

Therefore, the interactive interface of the online towerof-Hanoi-game-based courseware should be designed to achieve the following two requirements:

First, in order to make the operation specified and visualized, the courseware set up a game instruction zone, every step of the students' operation are recorded and stored and can be presented to the students. The effect of this part is shown in (1) of Fig. 2.

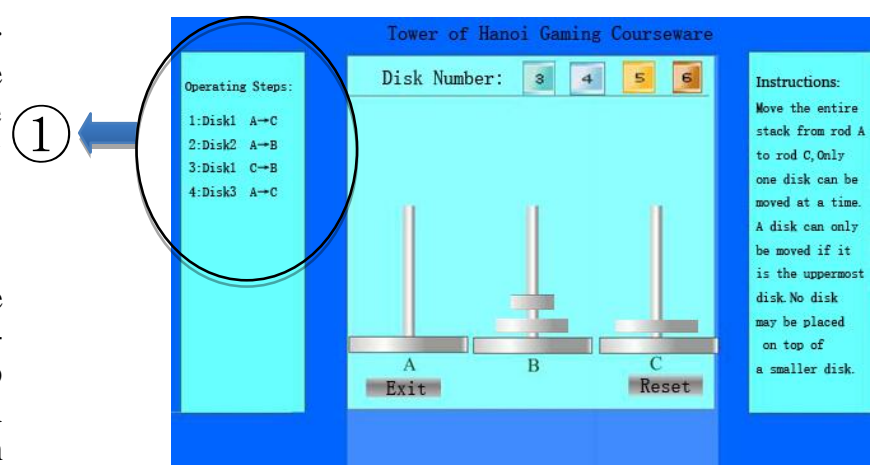

Figure 2. The screen shot of the running game

In addition, in order to achieve a good humancomputer interaction, in the appropriate operating courseware will ask the appropriate questions. That is, to design a questions presentation zone. When students are successful in moving the disks, the right part of the courseware will switch immediately from tips zone to 
questions presentation zone. The main role of the questions presentation zone is to enable the students master the principle to be mastered in the exploration through appropriate questions interaction, achieve the clearance model of online games, so that to stimulate student interest in learning and desire for knowledge. This part is the key of "edutainment". This part of the structure is also the use of text boxes of component library to achieve real-time interaction, the effect of which is shown in (2) of Fig. 3.

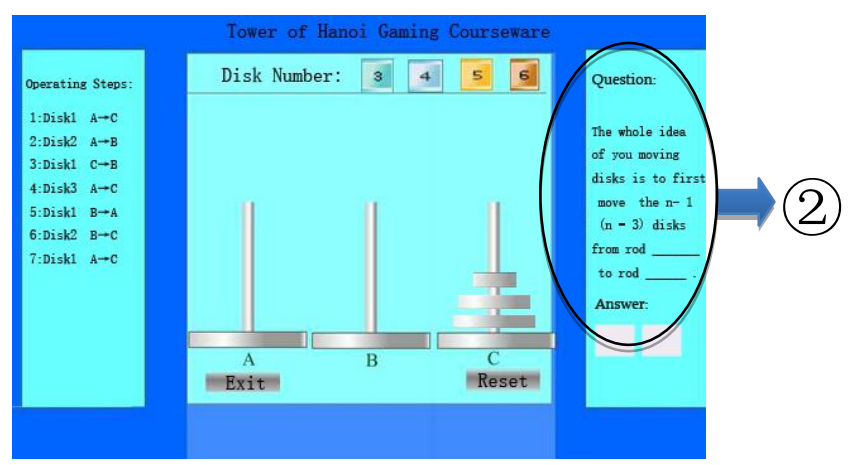

Figure 3. The screen shot of the questions presentation zone

\section{Interactive Design}

Interaction design is the core of online tower-of-Hanoigame-based courseware. Interaction can be achieved via HTML 、 HTXT and Hot spots. Convenient interaction allows students to acquire knowledge and to grasp the rhythm in an intuitively, rational, systematic and comprehensive way, and create effective real-time communication between teaching and learning. Bulgarian

educators Lozanov believes that flexible and interactive learning environment allows students to learn in an unknowingly, pleasant and efficient manner. ${ }^{[7]}$ In view of this, interaction design of the online tower-of-Hanoigame-based courseware should focus on the following aspects:

(1) Learning task: under the appropriate prompt, move through the button to select the number of dishes.

(2) In the process of moving the dish must ensure two things: First, the students can use the mouse to fast move the disks; Second, if students do not follow the requirements of moving disks, prompt the error so that students in a timely manner to correct the error.

(3) When carrying out the appropriate steps, courseware should exhibit appropriate questions, which is the focus of interaction design. The students can only continue the game by correctly answer questions, in order to continue exploratory study.

(4) Helpful information should be shown in a timely manner when needed. If there comes to a problem that confused the student, he/she can click the "Help" button to obtain proper ideas and methods to solve the problem. Help design is very important. It prevents the students from losing interest in learning for not getting appropriate help.

With the above design, the courseware will be able to provide virtual operating scenarios. Firstly, students will read the purpose of learning through Home page of the courseware, that is, to let students to do three and four disks move in the class, and then they can conclude the principle of recursion. Moving 5 and 6 disks is homework. Students can choose to move three disks at first. After they click the disks number button, A rod in the courseware center play area will appear three disks, game instruction zone will appear on the right side of courseware area to point out the considerations, and the left side will appear step displaying zone, in which every step of the students' operation will be marked and recorded so that the students can think about them and summarized the whole idea of the courseware. This process is shown in Fig. 2, when the students complete the whole task, the game will give the "succeed!" sign.

Then game instruction zone will change into questions presentation zone as shown in FIG. 3, and the questions will pop up inside the zone, continue to let students to answer questions and explore disciplinarian as well as solutions to the problem. The questions are presented by shallow to deep.

For example, when the students have finished moving three disks, the question presentation zone immediately raised a question of " The whole idea of you moving disks is to first move the $n-1 \quad(n=3)$ disks from rod to rod __ Only when the student answered a question correctly before they can continue to answer the next question. After answering all the questions on the right, the students can use the "Reset" button to re-play, or click on the "Continue" button to move the four disks task. The steps and processes of four-disk task are mostly the same like we mentioned above, but after successfully answering all the questions, the courseware will direct the students into law summary zone, as shown in Fig. 4. By summing up the problem step by step, the students will be able to summarize the essence of the principle of recursion from the game. That is, if you want to solve $\mathrm{N}$ issues, you should first solve the final one, and then the remaining $\mathrm{N}$ 1 issues. The same method could be applied to the remaining issues: first the $\mathrm{N}-1$ issue, then the remaining $\mathrm{N}$ 2 issues. Then continue this process until the number of issues needed to be resolved reach the number 0 . All of this is a natural process of moving.

Teaching practice has proved that this online tower-ofHanoi-game-based courseware can achieve the desired effect of teaching. By playing the game, student can understand the recursion principle in a more effective way comparing to learn via lectures and textbook, because the experience gained through the game is direct experience.

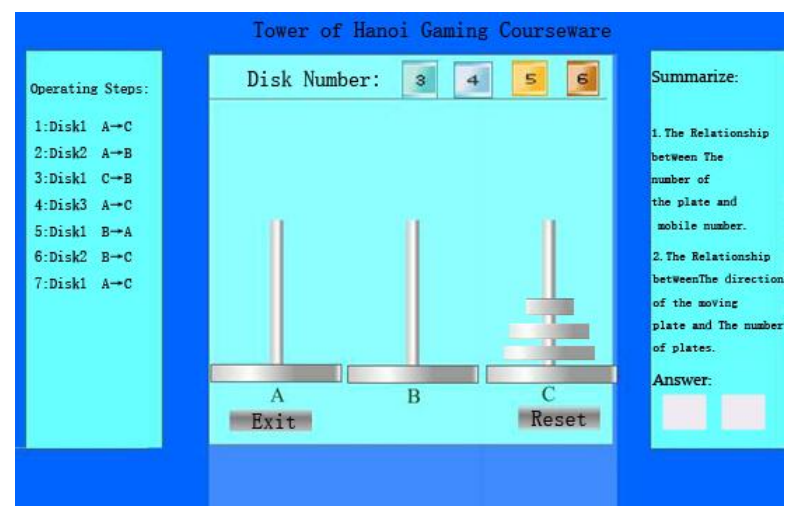

Figure 4. The screen shot of the law summary zone 


\section{IMPLEMENTATION OF ONLINE TOWER-OF-HANOI- GAME-BASED COURSEWARE}

The manufacturing process of online tower-of-Hanoigame-based courseware is a relatively complicated process, which requires not only strictly compliance with the above requirements but also widely comparison of different software technologies ${ }^{[8]}$. Then we selected the appropriate technology to implement. After widely researched and analyzed numerous network programming software, Flash was selected as courseware core developing software for its small size, flexibility and strong compatibility[8,9]. Vb.net technology is a powerful internet-based framework technique; therefore, building the outer frame of the courseware with vb.net technology would meet the requirements.

Concrete courseware implementation process was as follows:

\section{A. Modeling}

D The main task of this phase was to model rods and disks, which could be implemented by 3D- MAX modeling, and then exported them in image format..

\section{B. Constructing elements}

- (1) We imported the preceding model into Flash and build the rods and disks.

- (2) We constructed interactive buttons, applying the gradient effect provided by Flash could implement great visual effects.

\section{Layer assigning}

(1) We created a background layer, and placed the rod models and interactive buttons on the background layer.

(2) We created moving layers, placed the previous constructive disk-number-select-buttons in the appropriate location, moved the reset button to the bottom right corner, and then put the "end game" button in the bottom left corner of the layer.

(3) We created Procedure display layers. The main job of this layer is to record the students' operation steps and tip them up to the next step, so that they can sum up the law and master the knowledge points. We can use the text box in component library to implement this layer.

(4) We created game instructions layer. The main role of this layer was to give instructions of how to play the game, which would be shown before the students start the game by choosing disk number.

(5) We created questions display layer, as shown in Fig. 3

(6) We created law summary layer. The main role of this layer was to help the students to summarize the regularity of the game based on the answers they have made. Through a step-by-step guidance, this layer would help the students to summarize their exploration, so that the students can really understand recursion problem and the solution, and implement the full sense of exploratory self-study. ${ }^{[9]}$

\section{Code Writing}

The courseware should allow students to set different number of disks to begin the game according to the number they selected. In this section, we referenced variable $\mathrm{mc}$ to receive button action. on (press)

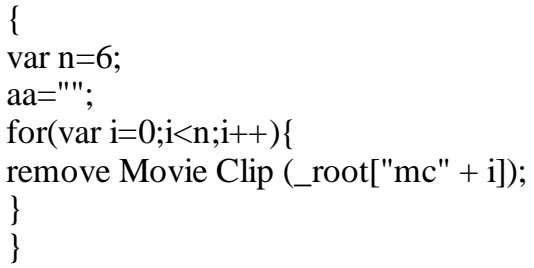

\section{E. . Debugging and releasing the courseware}

After ensuring the courseware can achieve the expected functions and tasks, we saved it and named it by "Tower of Hanoi game courseware" and then chose "publish" in the file menu to publish to the Internet.

\section{CONCLUSION}

Online game-based courseware has broken the traditional dull and boring mode of teaching and makes the tedious teaching process full of vigor and vitality. ${ }^{[10]}$

We first put this online game based courseware used in teaching, the students showed great enthusiasm on this new kind of learning. The students learned relaxed and happy, made joyful and pleasant progress, and fully affirmed the teaching effectiveness of the online tower-ofHanoi-game-based courseware.

\section{ACKNOWLEDGMENT}

Grant support: The authors and their work were Supported by Guangdong Society of Vocational and Technical Education(2015 general), grant no.: GDGZ15Y049.

\section{REFERENCES}

[1] He Qiang, Yao Sheng-guo, Cheng Yanli, et al. Design and Research on Online Gaming Courseware[J]. Experiment Science and Technology. 2013;4.

[2] He Ke-kang. On Deepening Reform of Modern Education Technology and Education[J]. E-education Research. 2014;(2).

[3] Li Jia, Wang Hai-ping. Explore the educational function of the network game[J]. Journal of Neijiang Normal University. 2013; (20).

[4] Xu Yan-zhuang. Development and application of computer-aided instruction and courseware: Higher Education Press; 2010.

[5] Zhao Xi, Dai Xin-lai. Design Principles and Applied Research of Gaming Courseware Based on Autonomous Learning[J]. Primary and Middle School Educational Technology. 2011;7.

[6] Wikipedia. Tower of Hanoi. https://en.wikipedia.org/wiki/Tower_of_Hanoi.

[7] Fang Fang, Gu Hui-zhong. Situation Analysis of educational games[J]. Information technology. 2006;7.

[8] Zhang Pei, An Jie. Flash8 Game Programming Tutorial Examples. Beijing: Machinery Industry Press; 2011.

[9] Zhou Jing-qian. Implementation of Flash Multimedia Network Courseware[J]. Distance Education in China. 2011;(5).

[10] Guo Yu-hua. Early Research Of Online Games and Educational Integration[J]. Exam Magazine. 2014;(29) 